\title{
Cigarette brand loyalty among smokers in six European countries: Findings from the EUREST-PLUS ITC Europe Surveys
}

\author{
Sarah O. Nogueira ${ }^{1,2,3}$, Olena Tigova ${ }^{1,2}$, Yolanda Castellano ${ }^{1,2}$, Ute Mons ${ }^{4}$, Christina N. Kyriakos ${ }^{5,6}$, Ann McNeill, \\ Antigona C. Trofor ${ }^{8,9}$, Witold A. Zatoński10,11, Krzysztof Przewoźniak ${ }^{10,12}$, Tibor Demjén ${ }^{13}$, Yannis Tountas ${ }^{14}$, Anne \\ C. K. Quah ${ }^{15,16}$, Geoffrey T. Fong ${ }^{15,16}$, Marcela Fu ${ }^{1,2}$, Constantine I. Vardavas ${ }^{5,6}$, Esteve Fernández ${ }^{1,2,3}$, on behalf of the \\ EUREST-PLUS consortium*
}

\section{ABSTRACT}

INTRODUCTION This study aims to describe the degree of smokers' loyalty to a specific brand of tobacco products and the variables related to choosing a specific brand among smokers in six European countries.

METHODS A cross-sectional analysis was conducted for a representative sample of adult smokers from Germany, Greece, Hungary, Poland, Romania, and Spain (approximately 1000 smokers per country). The prevalence of smokers' having a usual brand of cigarettes smoked (factory-made or roll-yourown cigarettes), the brand of choice, the factors for choosing a specific brand and the degree of loyalty to that brand (not at all, a little, somewhat and a lot) were assessed by country, sociodemographics and smoking-related variables.

RESULTS In total, $86.6 \%$ of the smokers reported having a usual brand. In three out of the six countries, one brand holds the loyalty of between $17.8 \%$ and $24.5 \%$ of the smokers that reported having a usual brand for factory-made cigarettes. Most participants reported being loyal 'a lot' to their brand of choice (44.4\%). The reasons most reported for choosing a cigarette brand were the taste $(83.2 \%)$ and the price $(51.7 \%)$. CONCLUSIONS Brand loyalty is high among factory-made and roll-your-own cigarette smokers in six European countries. Future research on longitudinal trends of brand loyalty to evaluate the effect of tobacco control policies in these European countries is warranted.

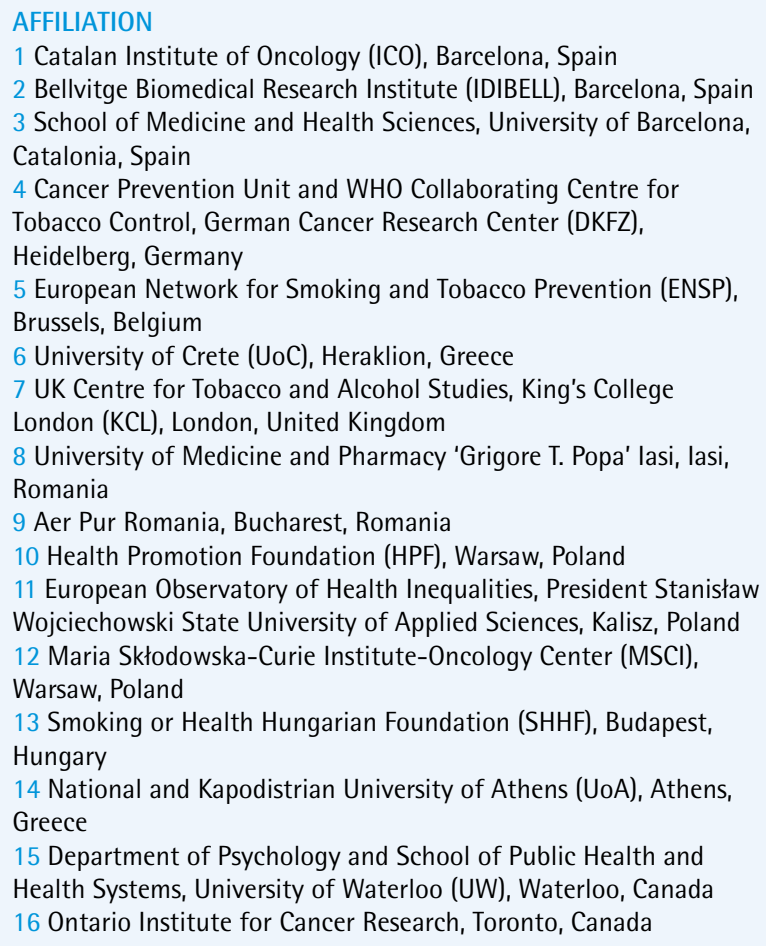

Esteve Fernández. Tobacco Control Unit, Catalan Institute of Oncology (ICO), Av. Granvia de L'Hospitalet, 199-203, 08908 L'Hospitalet de Llobregat, Barcelona, Spain.

E-mail: efernandez@iconcologia.net

KEYWORDS

brand loyalty, brand choice, attachment, plain packaging, tobacco

Received: 27 July 2018

Revised: 28 September 2018

Accepted: 21 October 2018

\section{INTRODUCTION}

Tobacco was the cause of the death of around seven million people in $2017^{1}$, with an alarming rate of up to two deaths per three smokers ${ }^{2}$. Although it is such a lethal product, tobacco companies still achieve high success in marketing and selling 
tobacco. In fact, the six largest cigarette companies made a profit of approximately $\$ 10000$ per death from tobacco smoking, in $2015^{3}$. Understanding the factors influencing smokers' brand choice and their loyalty to a brand are important as countries develop and implement tobacco control strategies ${ }^{4}$, but there is still scarce academic research in this regard.

The European Union (EU) has become an increasingly restrictive market for tobacco products in recent years with the signature of the World Health Organization (WHO) Framework Convention on Tobacco Control (FCTC) $)^{5}$, the first public health treaty aiming to tackle some of the causes of the tobacco epidemic, and the approval of a new EU Tobacco Products Directive (TPD) (2014/40/EU), which aims to regulate several aspects surrounding tobacco products ${ }^{6}$. Both of the abovementioned regulations could affect whether and why smokers are loyal to a cigarette brand, although none of these regulations includes measures designed to directly influence brand loyalty.

Diminishing brand loyalty might be an effective pathway to tobacco control, considering brand loyalty has been found to be associated with a decline in the sense of identity smokers may have of being a smoker of a certain brand, and therefore sharing special characteristics with those that share the same brand of choice ${ }^{7,8}$. Such brand identity has been used by the tobacco industry as a means to maintain sales growth. This became clear with the disclosure of tobacco industry internal documents, which have shown that tobacco companies develop explicit marketing strategies to create meaningful identities through tobacco brands ${ }^{9}$. Similarly, there is theoretical support for the link between brand identity and the deflection of bad connotations and stigmatization associated with smoking ${ }^{10,11}$. The implementation of cigarette standardised packaging design was found to be associated with decreased brand identity, decreased positive brand stereotypes, decreased smoking behaviour and higher odds of quitting among smokers ${ }^{8}$.

This paper documents several aspects of tobacco brand loyalty, such as the degree of brand loyalty and variables associated with brand choice of tobacco products among smokers in Germany (DE), Greece (GR), Hungary (HU), Poland (PL), Romania (RO), and Spain (ES), countries where there are still no data about such aspects of brand loyalty.

\section{METHODS}

\section{Study design}

The EUREST-PLUS project aims to evaluate the implementation and impact of the TPD and WHO FCTC in six European Member States (MS). The cross-sectional data analysed here derive from Wave 1 of the EUREST-PLUS International Tobacco Control Policy Evaluation (ITC) survey, a longitudinal cohort study of smokers in DE, GR, HU, PL, RO, and ES ${ }^{12,13}$. The fieldwork for Wave 1 was conducted between June 2016 and September $2016^{14}$. The survey sample comprised 6011 (about 1000 per country) nationally representative adult (over 18 years old) cigarette smokers that had smoked more than 100 cigarettes in their lives. Further details including study design and recruitment can be found elsewhere ${ }^{12,13}$.

\section{Ethics}

This study's protocol was approved by the Office of Research Ethics at the University of Waterloo (Canada), and by the ethics committees of all the participant countries and partnering institutions. The EUREST-PLUS Project is registered in Clinicaltrials. gov (registration number NCT02773836).

\section{Measures}

\section{Brand loyalty measures}

Participants were asked: 'Do you have a usual brand and variety of cigarettes?'. Response options were 'yes' and 'no'. If they answered 'yes', they were asked the following questions to explore the degree of brand loyalty: 'To what extent are you committed to your regular brand of cigarettes?'. Answer options were 'not at all', 'a little', 'somewhat', 'a lot', 'don't know', and 'refused'. Those that answered 'don't know' and 'refused' were excluded from the analysis of the degree of loyalty and factors influencing the decision to choose a specific brand.

In addition, respondents were asked: 'What is your usual brand of factory-made cigarettes?' and 'What is your usual brand of roll-your-own cigarettes?' Two lists of brands of roll-your-own (RYO) and factorymade (FM) cigarettes had been previously developed for each country and the answers provided by the respondents were compared to those lists and 
categorized accordingly; if the brand mentioned was not in the list, the response was categorized as 'other brand'. Participants could also respond 'don't know' or 'refused' and those who chose one of these two options were excluded from the analysis.

\section{Reasons for brand loyalty}

Respondents were also asked: 'In choosing your usual brand, was part of your decision to smoke this brand based on any of the following: It may not be bad for your health? The price? How they taste? The look and feel of the pack? The tar and nicotine levels of the brand?'. The response options for each question were 'yes', 'no', 'don't know', and 'refused'. Those who answered 'don't know' or 'refused' were excluded from the analysis.

\section{Other measures}

Sociodemographic characteristics studied were country, sex (female and male), age group (18-24, $25-39,40-54,55$ years and older), and level of education (low, medium, high). Smoking behaviours were assessed with the following variables: smoking frequency (daily, occasional), cigarettes smoked per day $(\leq 10,11-20,21-30,>30)$, the type of cigarettes smoked (FM only, RYO only, both), and tobacco addiction, which was assessed with the Heaviness of Smoking Index (HSI; with categories low $=0-2$, moderate $=3-4$, and high $=5-6)^{14}$.

\section{Analysis}

Descriptive analyses were conducted to compute the prevalence of brand loyalty, the degree of loyalty (not at all, a little, somewhat, and a lot loyal), and the reasons influencing the decision for choosing their usual brand among smokers by country, sociodemographic and smoking-related variables. Pearson's chi-squared test was used to assess differences among groups. The overall most popular brands of RYO and FM cigarettes were identified by country. Additionally, multivariate logistic regression was used to compute adjusted odds ratios (AOR) and 95\% confidence intervals (CI) of the association of having a usual brand by sociodemographic variables. All the analysis incorporated the weights from the complex sampling design. Stata version 13 was used for the analyses.

\section{RESULTS}

\section{Usual brand}

Most respondents reported having a usual brand $(86.6 \%)$. Table 1 presents the results for the differences between smokers with and without a usual brand by sociodemographic characteristics and smoking-related characteristics. GR was the country with the highest prevalence of smokers loyal to a brand $(96.0 \%)$ while PL was the country with the lowest (73.9\%). Females were more likely to report having a usual brand than males $(88.8 \%$ vs $85.0 \%$; $\mathrm{AOR}=1.42,95 \%$ CI: $1.21-1.67)$. Smokers from the youngest age group were more likely to report having a usual brand than those who were older $(87.5 \%$ of $18-24$ group vs $83.2 \%$ of $\geq 55$ years group; AOR=1.51, 95\% CI: 1.06-2.17). In all, 88.6\%

Table 1. Differences between smokers with and without a usual brand by country, sociodemographic variables and smoking-related variables, $\mathrm{N}=6003$

\begin{tabular}{|c|c|c|c|c|c|c|c|c|c|}
\hline & \multicolumn{3}{|c|}{ Loyal to a brand } & \multicolumn{3}{|c|}{ Not loyal to a brand } & \multirow[b]{2}{*}{$A O R^{\circ}$} & \multirow[b]{2}{*}{$\left(95^{\circ} \circ \mathrm{Cl}\right)$} & \multirow[b]{2}{*}{ p } \\
\hline & n & $\%$ & $95^{\circ} \circ \mathrm{CI}$ & n & $\%$ & $95^{\circ} \% \mathrm{CI}$ & & & \\
\hline All & 5226 & 86.6 & (85.2-88.0) & 777 & 13.4 & $(12.0-14.8)$ & & & \\
\hline \multicolumn{10}{|l|}{ Country } \\
\hline Germany & 844 & 81.8 & (77.6-85.9) & 158 & 18.2 & $(14.1-22.4)$ & & Ref. & \\
\hline Greece & 956 & 96.0 & (94.4-97.7) & 43 & 4.0 & $(2.3-5.6)$ & 5.05 & (3.04-8.40) & $<0.001$ \\
\hline Hungary & 918 & 91.0 & (87.5-94.6) & 82 & 9.0 & $(5.4-12.5)$ & 2.38 & $(1.38-4.09)$ & 0.002 \\
\hline Poland & 759 & 73.9 & (69.5-78.3) & 241 & 26.1 & $(21.7-30.5)$ & 0.41 & $(0.26-0.64)$ & $<0.001$ \\
\hline Romania & 833 & 85.6 & (82.1-89.1) & 168 & 14.4 & $(10.9-17.9)$ & 0.79 & $(0.49-1.26)$ & 0.322 \\
\hline Spain & 916 & 91.3 & (88.7-93.9) & 85 & 8.7 & $(6.1-11.3)$ & 1.99 & $(1.24-3.20)$ & 0.005 \\
\hline \multicolumn{10}{|l|}{ Sex } \\
\hline Male & 2718 & 85.0 & (83.2-86.7) & 454 & 15.0 & $(13.3-16.8)$ & & Ref. & \\
\hline Female & 2508 & 88.8 & (87.4-90.3) & 323 & 11.2 & $(9.7-12.6)$ & 1.42 & $(1.21-1.67)$ & $<0.001$ \\
\hline
\end{tabular}


Table 1. Continued

\begin{tabular}{|c|c|c|c|c|c|c|c|c|c|}
\hline & \multicolumn{3}{|c|}{ Loyal to a brand } & \multicolumn{3}{|c|}{ Not loyal to a brand } & \multirow[b]{2}{*}{ AOR* } & \multirow[b]{2}{*}{$\left(95^{\circ} \% \mathrm{CI}\right)$} & \multirow[b]{2}{*}{$p$} \\
\hline & n & $\%$ & $95^{\circ} \mathrm{CI}$ & n & $\%$ & $95^{\circ} \mathrm{CO}$ & & & \\
\hline \multicolumn{10}{|l|}{ Age (years) } \\
\hline $18-24$ & 439 & 87.5 & (84.4-90.6) & 67 & 12.5 & $(9.4-15.6)$ & 1.51 & $(1.06-2.17)$ & 0.024 \\
\hline $25-39$ & 1557 & 88.1 & $(85.9-90.3)$ & 212 & 11.9 & $(9.7-14.1)$ & 1.47 & $(1.14-1.90)$ & 0.003 \\
\hline $40-54$ & 1763 & 87.4 & (85.7-89.2) & 240 & 12.6 & $(10.8-14.3)$ & 1.41 & $(1.14-1.75)$ & 0.002 \\
\hline$\geq 55$ & 1467 & 83.2 & (80.7-85.7) & 258 & 16.8 & $(14.3-19.3)$ & & Ref. & \\
\hline \multicolumn{10}{|c|}{ Level of education } \\
\hline Low & 1931 & 87.4 & (85.4-89.4) & 278 & 12.6 & $(10.6-14.6)$ & & Ref. & \\
\hline Medium & 2668 & 85.3 & (83.5-87.1) & 434 & 14.7 & $(12.9-16.5)$ & 1.12 & $(0.90-1.40)$ & 0.296 \\
\hline High & 596 & 90.2 & (87.4-93.0) & 60 & 9.8 & $(7.0-12.6)$ & 1.51 & $(0.98-2.32)$ & 0.060 \\
\hline \multicolumn{10}{|c|}{ Type of cigarettes smoked } \\
\hline Factory-made & 3944 & 88.6 & (87.1-90.1) & 510 & 11.4 & $(9.9-12.9)$ & 2.87 & $(2.11-3.89)$ & $<0.001$ \\
\hline Roll-your-own & 916 & 85.4 & (81.7-89.1) & 144 & 14.6 & $(10.9-18.3)$ & 1.10 & $(0.77-1.56)$ & 0.598 \\
\hline Both & 366 & 73.0 & $(68.6-77.4)$ & 122 & 27.0 & $(22.6-31.4)$ & & Ref. & \\
\hline \multicolumn{10}{|c|}{ Frequency of smoking } \\
\hline Daily & 5015 & 87.4 & (86.0-88.8) & 696 & 12.6 & $(11.2-14.0)$ & & & \\
\hline Occasional & 211 & 70.9 & $(65.0-76.9)$ & 81 & 29.1 & $(23.1-35.0)$ & & & \\
\hline \multicolumn{10}{|c|}{ Cigarettes smoked/day } \\
\hline$\leq 10$ & 1795 & 86.2 & $(84.3-88.1)$ & 288 & 13.8 & $(11.9-15.7)$ & & & \\
\hline $11-20$ & 2699 & 87.4 & (85.7-89.2) & 375 & 12.6 & $(10.8-14.3)$ & & & \\
\hline $21-30$ & 453 & 84.1 & $(80.0-88.3)$ & 70 & 15.9 & $(11.7-20.0)$ & & & \\
\hline$>30$ & 274 & 85.7 & $(81.3-90.1)$ & 40 & 14.3 & $(9.9-18.7)$ & & & \\
\hline \multicolumn{10}{|c|}{ Tobacco addiction** } \\
\hline Low & 2077 & 88.0 & $(86.1-89.8)$ & 280 & 12.0 & $(10.2-13.9)$ & 1.31 & $(0.94-1.81)$ & 0.113 \\
\hline Moderate & 2480 & 87.7 & $(85.9-89.4)$ & 332 & 12.3 & $(10.6-14.1)$ & 1.57 & $(1.17-2.11)$ & 0.002 \\
\hline High & 440 & 83.5 & $(79.8-87.3)$ & 77 & 16.5 & $(12.7-20.2)$ & & Ref. & \\
\hline
\end{tabular}

AOR: adjusted odds ratio, $\mathrm{Cl}$ : confidence interval. *Adjusted odds ratios derived from multi-level logistic regression, adjusted for age, sex, educational level, area of residence, and tobacco addiction. ${ }^{* *}$ Measured with the Heaviness of Smoking Index: $0-2=l o w ; 3-4=$ moderate; $5-6=$ high.

of smokers of FM cigarettes, $85.4 \%$ of RYO cigarettes smokers and $73.0 \%$ of smokers of both types of cigarettes reported having a usual brand. The difference between those smoking both and those smoking FM cigarettes was statistically significant (AOR=2.87, 95\% CI: 2.11-3.89). Of the daily and occasional smokers, $87.4 \%$ and $70.9 \%$ reported having a usual brand, respectively.

\section{Brands most used across countries}

The most popular brand in the overall sample was Malboro (14.65\%). In three out of the six countries, Marlboro was the usual brand for between 17.8\% and $24.5 \%$ of smokers that reported having a usual brand for FM cigarettes, and it was the most popular in four of the six countries. The second most popular brand, Kent, reaches this position because of RO smokers $(23.3 \%)$, but was not highly reported as the brand of choice in the other five countries. RO participants were the ones reporting the most disperse results, with $76.7 \%$ of the smokers being loyal to brands other than the most popular ones in the overall sample. Brand loyalty for RYO was more dispersed, with Marlboro being the only usual brand for more than $10 \%$, in two out of the six countries.

\section{Degree of loyalty to usual brand}

Table 2 presents the self-reported smokers' degree of loyalty to their usual brand by country, sociodemographics and tobacco addiction. The degree of loyalty to a brand was significantly different within all the studied variables $(p<0.001)$, except for sex $(p=0.413)$. Most participants reported being 'a lot' loyal to their brand of choice (44.4\%), 34.3\% reported being 'somewhat' loyal, $16.2 \%$ 'a little', and $5.1 \%$ 'not at all' loyal. Participants in GR (51.5\%), 
Table 2. Degree of loyalty to the brand by country, sociodemographic variables and tobacco addiction, $\mathrm{N}=5196$

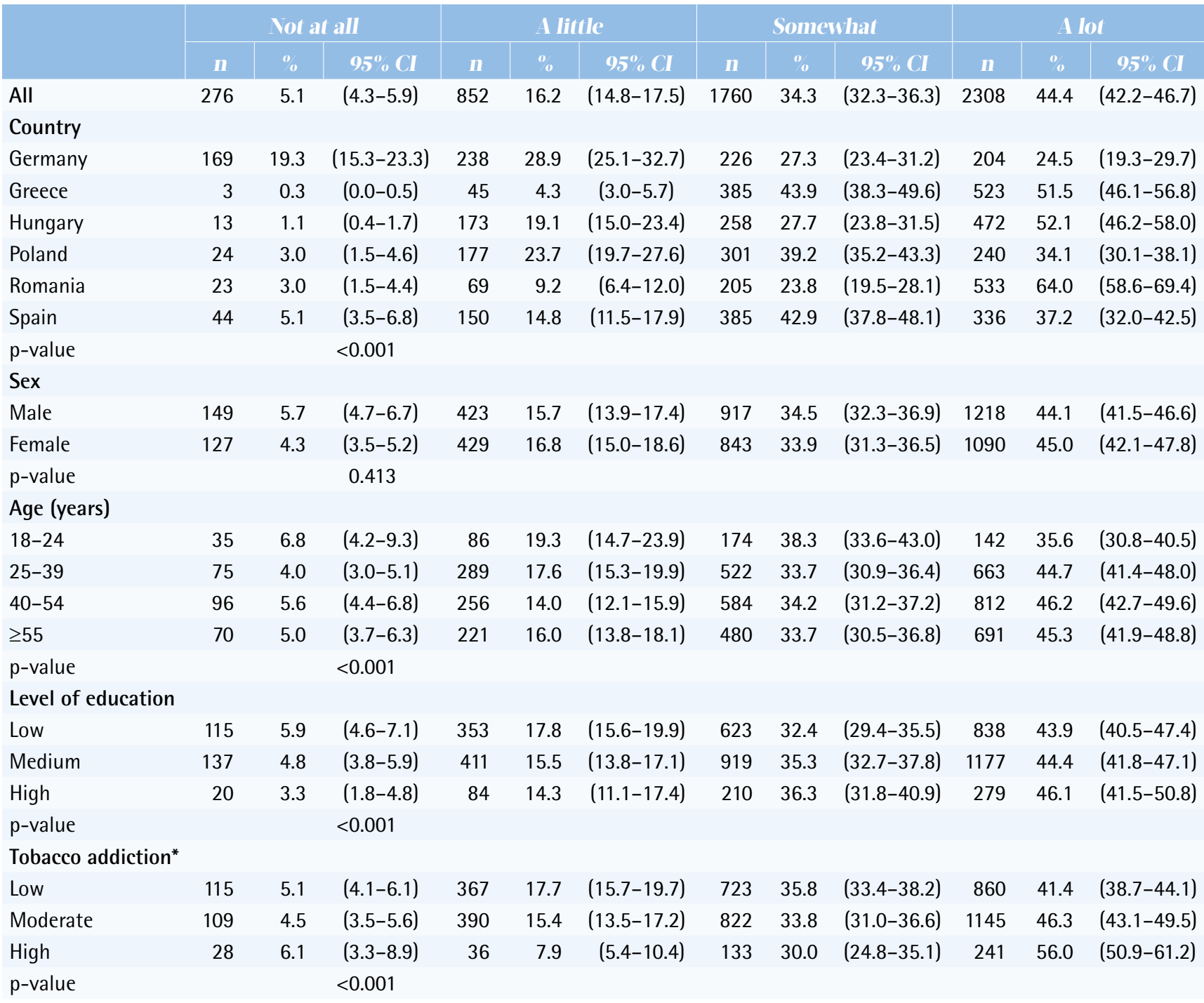

$\mathrm{Cl}$ : confidence interval. *Measured with the Heaviness of Smoking Index: $0-2=10 w ; 3-4=$ moderate; 5-6=high

HU (52.1\%), and RO (64\%) were the ones with the highest levels of loyalty to a brand, while those in DE had a homogeneous distribution across the four categories of brand loyalty. A gradient in the degree of brand loyalty was observed in participants across sexes, age groups, and levels of education. Participants across these three sociodemographic variables were between $3.3 \%$ and $6.8 \%$ 'not at all' loyal, between $14.0 \%$ and $19.3 \%$ 'a little' loyal, between $32.4 \%$ and $38.3 \%$ 'somewhat' loyal, and between $35.6 \%$ and $46.2 \%$ 'a lot' loyal to their brand of choice $(\mathrm{p}<0.001)$. Another noticeable gradient was observed among those reporting being 'a lot' loyal to a brand, varying from $41.4 \%$ for those less addicted to $56.0 \%$ of those highly addicted to nicotine $(\mathrm{p}<0.001)$.

\section{Reasons for choosing usual brand}

Table 3 presents the reasons that may influence the decision for loyalty to a specific brand by sociodemographic variables. Overall, the taste from the cigarette was the reason most cited by smokers $(83.2 \%)$ followed by the price $(51.7 \%)$, the tar and nicotine levels of the brand $(41.5 \%)$, the look and the feel of the pack $(23.2 \%)$, and the perception of being less harmful (21.4\%).

Female smokers were significantly more influenced than male smokers by the price ( $53.2 \%$ vs $50.5 \%$ ), the tar and nicotine levels ( $44.5 \%$ vs $39.2 \%$ ), the look and feel of the pack ( $25.5 \%$ vs $21.4 \%)$, and the cigarette harm perception (23.8\% vs $19.6 \%$ ). The younger the smokers the bigger the percentage of them reporting 
Table 3. Factors that may influence the decision to choose a specific brand by country and sociodemographic variables, $\mathrm{N}=6003$

\begin{tabular}{|c|c|c|c|c|c|c|c|c|c|c|c|c|c|c|c|}
\hline & \multicolumn{3}{|c|}{ The taste } & \multicolumn{3}{|c|}{ The price } & \multicolumn{3}{|c|}{$\begin{array}{l}\text { The tar and nicotine } \\
\text { levels of the brand }\end{array}$} & \multicolumn{3}{|c|}{$\begin{array}{c}\text { The look and feel of } \\
\text { the pack }\end{array}$} & \multicolumn{3}{|c|}{$\begin{array}{l}\text { It may not be as bad } \\
\text { for the health }\end{array}$} \\
\hline & $n$ & $\%$ & $95 \%$ CI & n & $\%$ & $95 \%$ CI & n & $\%$ & $95 \% \mathrm{CI}$ & In & $\%$ & $95 \% \mathrm{CI}$ & 11 & $\%$ & $95^{\circ} \circ \mathrm{CI}$ \\
\hline All & 4314 & 83.2 & (81.7-84.7) & 2666 & 51.7 & $(49.8-53.5)$ & 2104 & 41.5 & (39.3-43.8) & 1190 & 23.2 & $(21.3-25.1)$ & 1092 & 21.4 & $(19.5-23.4)$ \\
\hline \multicolumn{16}{|l|}{ Country } \\
\hline Germany & 746 & 89.6 & (86.9-92.2) & 370 & 45.3 & $(40.1-50.4)$ & 305 & 36.2 & (31.4-41.1) & 155 & 18.7 & $(14.7-22.7)$ & 116 & 13.8 & $(10.6-17.0)$ \\
\hline Greece & 858 & 90.4 & $(87.8-93.0)$ & 434 & 48.6 & $(43.6-53.5)$ & 583 & 59.5 & (52.9-66.2) & 295 & 30.2 & $(24.8-35.7)$ & 158 & 18.2 & $(12.1-24.3)$ \\
\hline Hungary & 707 & 78.4 & (73.5-83.4) & 628 & 69.1 & (64.7-73.6) & 340 & 38.2 & $(32.5-43.9)$ & 201 & 21.8 & (17.3-26.3) & 252 & 28.0 & $(23.4-32.6)$ \\
\hline Poland & 644 & 84.9 & (81.2-88.7) & 502 & 66.7 & $(61.9-71.5)$ & 283 & 39.7 & (33.9-45.6) & 199 & 26.4 & $(22.5-30.2)$ & 177 & 23.1 & (18.5-27.6) \\
\hline Romania & 606 & 73.1 & $(68.5-77.6)$ & 327 & 38.7 & $(34.5-42.9)$ & 442 & 57.4 & (52.9-61.9) & 256 & 33.8 & $(28.6-39.0)$ & 283 & 33.3 & $(29.0-37.6)$ \\
\hline Spain & 753 & 83.0 & (79.5-86.5) & 405 & 43.3 & $(38.5-48.1)$ & 151 & 17.4 & $(12.3-22.5)$ & 84 & 8.9 & $(5.3-12.5)$ & 106 & 13.2 & $(8.0-18.4)$ \\
\hline$p$-value & & & $<0.001$ & & & $<0.001$ & & & $<0.001$ & & & $<0.001$ & & & $<0.001$ \\
\hline \multicolumn{16}{|l|}{ Sex } \\
\hline Male & 2252 & 83.8 & $(81.9-85.6)$ & 1328 & 50.5 & $(48.3-52.8)$ & 1038 & 39.2 & $(36.5-41.9)$ & 573 & 21.4 & (19.2-23.5) & 526 & 19.6 & $(17.5-21.7)$ \\
\hline Female & 2062 & 82.6 & $(80.7-84.4)$ & 1338 & 53.2 & $(50.7-55.6)$ & 1066 & 44.5 & $(41.9-47.2)$ & 617 & 25.5 & $(23.1-27.9)$ & 566 & 23.8 & $(21.3-26.3)$ \\
\hline$p$-value & & & 0.579 & & & $<0.001$ & & & $<0.001$ & & & $<0.001$ & & & $<0.001$ \\
\hline \multicolumn{16}{|c|}{ Age (years) } \\
\hline $18-24$ & 354 & 80.9 & (76.3-85.5) & 208 & 46.1 & $(40.1-52.1)$ & 153 & 37.1 & $(31.6-42.5)$ & 123 & 28.1 & $(23.3-32.9)$ & 101 & 23.9 & $(19.5-28.4)$ \\
\hline $25-39$ & 1304 & 82.9 & (80.6-85.3) & 794 & 52.0 & $(49.2-54.9)$ & 620 & 42.1 & $(39.0-45.2)$ & 403 & 27.3 & $(24.2-30.3)$ & 302 & 21.1 & $(18.4-23.9)$ \\
\hline $40-54$ & 1456 & 83.3 & $(81.3-85.3)$ & 894 & 51.3 & $(48.5-54.1)$ & 743 & 41.2 & (38.1-44.2) & 357 & 19.5 & $(16.9-22.1)$ & 371 & 20.5 & $(17.6-23.3)$ \\
\hline$\geq 55$ & 1200 & 84.5 & (82.4-86.7) & 770 & 54.1 & $(51.0-57.2)$ & 588 & 43.3 & $(39.6-46.9)$ & 307 & 20.8 & (18.4-23.2) & 318 & 22.1 & (19.5-24.8) \\
\hline p-value & & & 0.340 & & & 0.230 & & & 0.045 & & & $<0.001$ & & & 0.236 \\
\hline \multicolumn{16}{|c|}{$\begin{array}{l}\text { Level of } \\
\text { education }\end{array}$} \\
\hline Low & 1570 & 81.7 & (79.3-84.2) & 1078 & 55.6 & $(52.8-58.3)$ & 678 & 36.0 & $(32.6-39.3)$ & 389 & 19.5 & $(16.9-22.2)$ & 379 & 20.4 & $(17.7-23.1)$ \\
\hline Medium & 2214 & 83.9 & $(82.2-85.5)$ & 1339 & 50.8 & $(48.2-53.4)$ & 1119 & 43.7 & $(40.8-46.6)$ & 640 & 24.9 & $(22.6-27.2)$ & 565 & 21.6 & (19.5-23.8) \\
\hline High & 507 & 85.4 & $(82.2-88.7)$ & 234 & 42.4 & $(37.2-47.6)$ & 292 & 49.8 & $(45.4-54.3)$ & 153 & 27.2 & $(23.0-31.3)$ & 140 & 23.9 & $(19.6-28.1)$ \\
\hline$p$-value & & & 0.083 & & & $<0.001$ & & & $<0.001$ & & & $<0.001$ & & & 0.086 \\
\hline \multicolumn{16}{|c|}{$\begin{array}{l}\text { Tobacco } \\
\text { addiction* }\end{array}$} \\
\hline Low & 1736 & 84.3 & $(82.2-86.3)$ & 994 & 49.2 & $(46.4-52.1)$ & 844 & 41.5 & $(38.7-44.4)$ & 479 & 23.8 & $(21.4-26.2)$ & 475 & 23.7 & $(21.1-26.3)$ \\
\hline Medium & 2024 & 82.4 & (80.4-84.4) & 1375 & 55.3 & $(53.1-57.6)$ & 996 & 41.6 & $(38.5-44.6)$ & 546 & 22.3 & $(20.0-24.5)$ & 493 & 20.3 & $(17.9-22.6)$ \\
\hline High & 356 & 81.4 & (77.5-85.3) & 218 & 49.2 & $(44.2-54.3)$ & 178 & 41.5 & $(36.1-46.9)$ & 94 & 22.1 & (16.7-27.6) & 59 & 14.3 & $(10.5-18.2)$ \\
\hline$p$-value & & & 0.261 & & & $<0.001$ & & & 0.969 & & & 0.623 & & & $<0.001$ \\
\hline
\end{tabular}

$\mathrm{Cl}$ : confidence interval. *Measured with the Heaviness of Smoking Index: 0-2=now; 3-4=moderate; 5-6=high.

the look and the feel of the pack as relevant $(28.1 \%$ of those between $18-24$ years of age vs $20.8 \%$ of those $\geq 55$ years). In contrast, the older the age group of a smoker the bigger the percentage reporting that they considered tar and nicotine levels in choosing a brand ( $43.3 \%$ of those $\geq 55$ years vs $37.1 \%$ of those between 18-24 years). These differences by age groups were statistically significant.

\section{DISCUSSION}

Overall, most smokers (86.6\%) reported having a usual brand, particularly daily smokers $(87.4 \%)$ and those highly educated (90.2\%). One brand was the most popular in four out of the six countries, holding the loyalty of less than a quarter of the smokers in these countries. Almost half of the smokers reported being loyal 'a lot' to a brand and only $5.1 \%$ reported having the lowest level of loyalty. Taste was reported by eight in ten as a factor that influences their loyalty, and five in ten mentioned price as an influential factor.

Smokers with the lowest educational level were less brand loyal and reported price as the main influential factor. Other studies have found similar 
results, with smokers with lower socioeconomical levels switching brands more frequently because of price differences, i.e. being less brand loyal ${ }^{15,16}$. One of these studies also found similar results in relation to level of nicotine addiction, with those more addicted to nicotine being more brand loyal than those less addicted ${ }^{16}$. One possible explanation for these results is that those less addicted are mostly occasional smokers and tend to share cigarette packs with other smokers making their choice more defined by the others.

Gender differences were observed in reporting brand loyalty and factors influencing it, with females being more frequently loyal to a brand and mentioning price, the levels of nicotine and tar, the look and feel of the pack, and the perceived potential harms as factors influencing their choice of a cigarette brand more than males. These results might be related to the fact that in the EU, in 2016, the gender pay gap (the average difference between the renumeration for men and women working) was $16.2 \%$ and all the countries in the study the gender pay gap was at least $15.3 \%$, except in RO $(5 \%)^{17}$. Evidence also presents women as more attentive to health-related issues and more likely to take action on these matters ${ }^{18-20}$. Additional evidence related to brand loyalty and gender differences, that might at least partially explain our results, is that the tobacco industry has systematically targeted women in their advertisements, associating brands with positive images of independence, self-care and success ${ }^{16,21,22}$.

Marlboro, the most popular choice of usual brand overall, was also the most popular choice for RYO and FM smokers in four out of the six countries. Marlboro was the most sold cigarette brand in 2016 in DE, GR, HU, and ES; with DE being the country with the most affordable Marlboro cigarettes, followed by ES, GR, and $\mathrm{HU}^{23-26}$. As the price was the second most cited reason for choosing a brand ( $51.7 \%$ of the sample), the increase in taxation of cigarettes could play a part in the decrease of brand loyalty in these countries.

A difference of approximately $20 \%$ prevalence was observed among the countries with the highest and lowest brand loyalty prevalence. This finding might point to cross-country differences in the implementation of tobacco control policies, such as bans on tobacco advertising. The EUREST-PLUS ITC
6E Survey shows that tobacco advertising, promotion and sponsorship tended to be noticed more often in countries with less restrictive regulation (e.g. DE and GR $)^{27}$. Another finding from the same EURESTPLUS ITC 6E Survey is that tobacco advertising exposure was widely prevalent outside and inside the points-of-sale in all six countries, including $\mathrm{HU}$ and RO, countries where bans on this advertising have been implemented ${ }^{27}$.

Taste of the cigarette was the factor most cited as a reason for choosing a brand by 8 in 10 smokers, followed by price (approximately 5 in 10 smokers), tar and nicotine levels for brand (4 in 10 smokers), look and the feel of the pack ( 2 in 10 smokers), and perception of harms ( 2 in 10 smokers). Data from the Eurobarometer also indicated that just under half of the smokers in the EU smoked cigarettes with special characteristics in $2017^{28}$. The most popular choices were the additive-free or organic cigarettes (17\%) and the light cigarettes (16\%). Our data point to the possibility that most smokers in Europe smoke the cigarettes they perceive as less harmful, even though there is no evidence for differences in the safety of combustible cigarettes ${ }^{29,30}$. Additionally, menthol flavour (8\%) and other flavours (7\%) were also identified in the Eurobarometer survey as consistently used by smokers. Therefore, these results reinforce the importance of the effective ban of flavourings in cigarettes established by the TPD, which should be fully implemented by $2020^{6}$.

Another measure that has been found to be related to brand loyalty is plain packaging ${ }^{8}$. It aims to standardise and eliminate the design and packaging characteristics that could mislead consumers, suggesting benefits in terms of less harm. Several studies provide evidence that it may reduce false beliefs that certain brands are less harmful and reduce pack and product appeal ${ }^{9,31,32}$. At the population level, plain packaging has already been proven to be effective in tackling tobacco consumption by lowering brand loyalty in Australia ${ }^{8}$. Additionally, Australian smokers were more likely to find their tobacco product packs less attractive, find their cigarettes less satisfying, and consider cigarette brands not differing in prestige, after one year of plain packaging implementation ${ }^{8}$.

In the EU, most of the measures transposed and implemented were not designed to undermine the 
relationship of smokers with their specific brand, which could act as a shield against tobacco cessation". Meanwhile, measures such as plain packaging, that could lead to a direct change in brand loyalty, are not compulsory and were left in charge of each country by the TPD ${ }^{33}$. This may result in delays and interference of the tobacco industry in the process of adopting plain packaging ${ }^{33}$.

Within the participating countries of the EUREST-PLUS Project, HU is going to implement plain packaging in 2018, which will enable a crosscountry comparison of the effects of such a measure in a longitudinal analysis. Longitudinal analysis of the EUREST-PLUS ITC Europe Survey will provide a clearer assessment of the potential association between the plain packaging policies implemented in some of the participating countries and changes in brand loyalty. Longitudinal analysis will also allow us to explore associations between brand loyalty and smoking cessation outcomes.

This study has some limitations, which should be noted. The pre-specified answer options for the questions might potentially exclude some important elements that influence brand choice and loyalty among smokers. The data used in this study are crosssectional and this design precludes any inference about the direction of causality. The question evaluating the reasons that influence a smokers' brand choice could be interpreted in two ways: 1) smokers choose their cigarettes because of their higher content of nicotine and tar, and 2) smokers choose their cigarettes because of their lower content of nicotine and tar as a healthier option. Although it seems intuitive they would choose the cigarettes with less concentrations of these compounds, the question could have been clearer. Some strengths should also be noted. This study used nationally representative samples of smokers in each of the six countries, making the generalisation of these results more feasible. Also, a standardised questionnaire and methodology were used for all the countries included in the current study, thus assuring comparability across countries.

\section{CONCLUSIONS}

This study provides a snapshot of cigarette brand loyalty across six European countries for the first time. The measures used here suggest that brand loyalty is high among smokers in these EU countries.
*EUREST-PLUS consortium members:

European Network on Smoking and Tobacco Prevention (ENSP), Belgium: Constantine I. Vardavas, Andrea Glahn, Christina N. Kyriakos, Dominick Nguyen, Katerina Nikitara, Cornel Radu-Loghin, Polina Starchenko

University of Crete (UoC), Greece: Aristidis Tsatsakis, Charis Girvalaki, Chryssi Igoumenaki, Sophia Papadakis, Aikaterini Papathanasaki,

Manolis Tzatzarakis, Alexander I. Vardavas

Kantar Public (TNS), Belgium: Nicolas Bécuwe, Lavinia Deaconu, Sophie Goudet, Christopher Hanley, Oscar Rivière

Smoking or Health Hungarian Foundation (SHHF), Hungary: Tibor Demjén, Judit Kiss, Piroska A. Kovács

Catalan Institut of Oncology (ICO); Bellvitge Biomedical Research Institute (IDIBELL), Spain: Esteve Fernández, Yolanda Castellano, Marcela Fu, Sarah O. Nogueira, Olena Tigova

Kings College London (KCL), United Kingdom: Ann McNeill, Katherine East, Sara C. Hitchman

Cancer Prevention Unit and WHO Collaborating Centre for Tobacco Control, German Cancer Research Center (DKFZ), Germany: Ute Mons, Sarah Kahnert

National and Kapodistrian University of Athens (UoA), Greece: Yannis Tountas, Panagiotis Behrakis, Filippos T. Filippidis, Christina Gratziou, Paraskevi Katsaounou, Theodosia Peleki, Ioanna Petroulia, Chara Tzavara

Aer Pur Romania, Romania: Antigona C. Trofor, Marius Eremia, Lucia Lotrean, Florin Mihaltan

European Respiratory Society (ERS), Switzerland; Goethe University Frankfurt, Germany: Gernot Rohde, Tamaki Asano, Claudia Cichon, Amy Far, Céline Genton, Melanie Jessner, Linnea Hedman, Christer Janson, Ann Lindberg, Beth Maguire, Sofia Ravara, Valérie Vaccaro, Brian Ward

Maastricht University, the Netherlands: Marc Willemsen, Hein de Vries, Karin Hummel, Gera E. Nagelhout

Health Promotion Foundation (HPF), Poland: Witold A. Zatoński, Aleksandra Herbeć, Kinga Janik-Koncewicz, Krzysztof Przewoźniak, Mateusz Zatoński University of Waterloo (UW); Ontario Institute for Cancer Research, Canada: Geoffrey T. Fong, Thomas K. Agar, Pete Driezen, Shannon Gravely, Anne C. K. Quah, Mary E. Thompson

\section{REFERENCES}

1. World Health Organization. WHO report on the global tobacco epidemic, 2017: Monitoring tobacco use and prevention policies. http://apps.who.int/iris/ bitstream/10665/255874/1/9789241512824-eng. pdf?ua $=1 \& u a=1$. Published, 2017. Accessed January 13, 2018.

2. Banks E, Joshy G, Weber MF, et al. Tobacco smoking and all-cause mortality in a large Australian cohort study: findings from a mature epidemic with current low smoking prevalence. BMC Med. 2015;13(1):38. doi:10.1186/s12916-015-0281-z

3. America Cancer Society, Vital Strategies. The Tobacco Atlas. Solution: Industry Strategies. https://tobaccoatlas. org/topic/industry-strategies/. Published, 2018. Accessed September 25, 2018.

4. Salloum RG, Goma F, Chelwa G, et al. Cigarette Price and Other Factors Associated with Brand Choice and Brand Loyalty in Zambia: Findings from the ITC Zambia Survey. Tob Control. 2015;24(3):iii33-iii40. doi:10.1136/tobaccocontrol-2014-051878

5. World Health Organization. WHO Framework Convention on Tobacco Control. http://www.who.int/ fctc/en. Published, 2003. Accessed February 21, 2018.

6. The European Commission. Revision of the tobacco products directive. https://ec.europa.eu/health/ 
tobacco/products/revision/. Published, 2014. Accessed May 24, 2018.

7. Dingle GA, Cruwys T, Frings D. Social Identities as Pathways into and out of Addiction. Front Psychol. 2015;6:1795. doi:10.3389/fpsyg.2015.01795

8. Webb H, Jones BM, McNeill K, et al. Smoke signals: The decline of brand identity predicts reduced smoking behaviour following the introduction of plain packaging. Addict Behav Reports. 2017;5:49-55. doi:10.1016/j.abrep.2017.02.003

9. Pechey R, Spiegelhalter D, Marteau TM. Impact of plain packaging of tobacco products on smoking in adults and children: an elicitation of international experts' estimates. BMC Public Health. 2013;13(1):18. doi:10.1186/1471-2458-13-18

10. Hoek J, Gendall P, Gifford H, et al. Tobacco branding, plain packaging, pictorial warnings, and symbolic consumption. Qual Health Res. 2012;22(5):630-639. doi:10.1177/1049732311431070

11. Mussweiler T, Gabriel S, Bodenhausen GV. Shifting social identities as a strategy for deflecting threatening social comparisons. J Pers Soc Psychol. 2000;79(3):398409. doi:10.1037/0022-3514.79.3.398

12. Fong GT, Thompson ME, Boudreau C, et al. The Conceptual Model and Methods of Wave 1 (2016) of the EUREST-PLUS ITG 6 European Countries Survey. Tob Induc Dis. 2018;16(Suppl 2:A3). doi:10.18332/tid/99881

13. Vardavas CI, Bécuwe N, Demjén T, et al. Study Protocol of European Regulatory Science on Tobacco (EUREST-PLUS): Policy implementation to reduce lung disease. Tob Induc Dis. 2018;16(Suppl 2:A2). doi:10.18332/tid/93305

14. Heatherton TF, Kozlowski LT, Frecker RC, Rickert W, Robinson J. Measuring the heaviness of smoking: using self-reported time to the first cigarette of the day and number of cigarettes smoked per day. British Journal of Addiction. 1989;84(7):791-799. doi:10.1111/j.1360-0443.1989.tb03059.x

15. Cowie GA, Swift E, Partos T, Borland R. Quitting activity and tobacco brand switching: findings from the ITC-4 Country Survey. Aust N Z J Public Health. 2015;39(2):109-113. doi:10.1111/1753-6405.12323

16. Cowie GA, Swift E, Borland R, Chaloupka FJ, Fong GT. Cigarette brand loyalty in Australia: findings from the ITC four country survey. Tob Control. 2013;23:i73-i79. doi:10.1136/tobaccocontrol-2013-051071

17. Eurostats statistics explained. Gender pay gap statistics. http://ec.europa.eu/eurostat/statistics-explained/index. php/Gender_pay_gap_statistics\#cite_note-1. Published, 2018. Accessed May 29, 2018.

18. Verbrugge LM. Gender and health: an update on hypotheses and evidence. J Health Soc Behav. 1985;26(3):156-182. doi:10.2307/2136750

19. Courtenay WH. Constructions of masculinity and their influence on men's well-being: a theory of gender and health. Soc Sci Med. 2000;50(10):1385-1401. doi:10.1016/S0277-9536(99)00390-1

20. Trofor AC, Man MA, Marginean C, Dumitru F, Trofor L. Smoking cessation for free: outcomes of a study of three Romanian clinics. Open Med. 2016;11(1):605610. doi:10.1515/med-2016-0098

21. Toll BA, Ling PM. The Virginia Slims identity crisis: an inside look at tobacco industry marketing to women. Tob Control. 2005;14(3):172-180. doi:10.1136/tc.2004.008953

22. Brandt AM. Recruiting women smokers: the engineering of consent. J Am Med Womens Assoc. 1996;51(1-2):6366.

23. World Health Organization. WHO report on the global tobacco epidemic, 2017. Country profile Germany. http://www.who.int/tobacco/surveillance/policy/ country_profile/deu.pdf?ua=1. Published, 2017. Accessed February 26, 2018.

24. World Health Organization. WHO report on the global tobacco epidemic, 2017. Country profile Greece. http:// www.who.int/tobacco/surveillance/policy/country_ profile/grc.pdf?ua=1. Published, 2017. Accessed February 26, 2018.

25. World Health Organization. WHO report on the global tobacco epidemic, 2017. Country profile Hungary. http://www.who.int/tobacco/surveillance/policy/ country_profile/hun.pdf?ua=1. Published, 2017. Accessed February 26, 2018.

26. World Health Organization. WHO report on the global tobacco epidemic, 2017. Country profile Spain. http:// www.who.int/tobacco/surveillance/policy/country_ profile/esp.pdf?ua=1. Published, 2017. Accessed February 26, 2018.

27. Kahnert S, Demjén T, Tountas Y, et al. Extent and correlates of self-reported exposure to tobacco advertising, promotion and sponsorship in smokers: Findings from the EUREST-PLUS ITC Europe Surveys. Tob Induc Dis. 2018;16(Suppl 2:A7). doi:10.18332/tid/94828

28. Special Eurobarometer 458. Attitudes of Europeans towards tobacco and electronic cigarettes. https:// ec.europa.eu/commfrontoffice/publicopinion/index. cfm/ResultDoc/download/DocumentKy/79002. Published, 2017. Accessed May 29, 2018.

29. Shahab L, West R, McNeill A. A comparison of exposure to carcinogens among roll-your-own and factory-made cigarette smokers. Addict Biol. 2009;14(3):315-320. doi:10.1111/j.1369-1600.2009.00157.x

30. Risks associated with smoking cigarettes with low machine-measured yields of tar and nicotine. 2001: U.S. Dept. of Health and Human Services, Public Health Service, National Institutes of Health, National Cancer Institute; 2001. file://catalog.hathitrust.org/ Record/011346682. Accessed July 27, 2018. 
31. Brennan E, Durkin S, Coomber K, Zacher M, Scollo M, Wakefield M. Are quitting-related cognitions and behaviours predicted by proximal responses to plain packaging with larger health warnings? Findings from a national cohort study with Australian adult smokers. Tob Control. 2015;24(Suppl 2):ii33-ii41. doi:10.1136/tobaccocontrol-2014-052057

32. Wakefield M, Coomber K, Zacher M, Durkin S, Brennan E, Scollo M. Australian adult smokers' responses to plain packaging with larger graphic health warnings 1 year after implementation: results from a national crosssectional tracking survey. Tob Control. 2015;24(Suppl 2):ii17-ii25. doi:10.1136/tobaccocontrol-2014-052050

33. Vardavas C, Filippidis FT, Ward B, et al. Plain packaging of tobacco products in the European Union: an EU success story? Eur Respir J. 2017;50(5). doi:10.1183/13993003.01232-2017
CONFLICTS OF INTEREST

The authors declare that they have no competing interests, financial or otherwise, related to the current work. K. Przewoźniak reports grants and personal fees from the Polish League Against Cancer, outside the submitted work. C. I. Vardavas reports that he is the Strategic Development Editor of TID and that there are no conflicts of interest with this current work. The rest of the authors have also completed and submitted an ICMJE form for disclosure of potential conflicts of interest.

\section{FUNDING}

The EUREST-PLUS project has received funding from the European Union's Horizon 2020 research and innovation programme under grant agreement No 681109 (CIV) and the University of Waterloo (GTF). Additional support was provided to the University of Waterloo by the Canadian Institutes of Health Research (FDN-148477). GTF was supported by a Senior Investigator Grant from the Ontario Institute for Cancer Research. SON, EF, MF, OT and YC are supported by the Ministry of Universities and Research, Government of Catalonia (2017SGR319). EF was supported by the Instituto de Salud Carlos III, Government of Spain (INT16/00211 and INT17/00103), co-funded by the European Regional Development Fund (FEDER). SON has received financial support through the 'La Caixa' INPHINIT Fellowship Grant for Doctoral studies at Spanish Research Centres of Excellence, 'La Caixa' Banking Foundation, Barcelona, Spain and funding from the European Union's 2020 research and innovation programme under the Marie SklodowskaCurie grant agreement.

PROVENANCE AND PEER REVIEW

Commissioned; externally peer reviewed. 